\title{
EDUCAÇÃO FÍSICA: O ENSINAR E O APRENDER
}

\author{
Raquel Stela Sá SIEBERT*
}

\begin{abstract}
A democracia liberal permite escolher, declara virtuoso, o educador. Isso é uma piada! A escolha é simples. A vida planejada pela elite no poder, a marcha prudente entre os pregos, ou então, a revolta com os riscos que ela comporta. Quer se trate da igualdade econômica, da igualdade de oportunidades, da igualdade no respeito, a igualdade não existe na civilização judaico-cristã. (Maurice Joyeux)
\end{abstract}

\section{INTRODUÇÃO}

$\mathrm{Na}$ análise das relações entre Educação Física e o processo de conhecimento que efetuei quando da elaboração de minha dissertação de mestrado cheguei à conclusão que não é possível desenvolver qualquer teoria pedagógica sem que se interprete claramente o projeto de homem/mundo que se deseja. É ingênuo pensar que se conhece sem que haja uma análise histórica do conhecimento, pois o mesmo não se dá em uma sociedade sem lugar e sem tempo. É necessário saber sempre os problemas ligados ao tempo e lugar nos quais os processos educativos se situam e são realizados. O que interessa, pois, é compreender o homem situado e datado, logo um ser de relações com o mundo, dando-se. Neste sentido não é possivel que se pense uma Educação Física neutra. O que quero dizer é que ou trabalhamos no sentido da domesticação do indivíduo ou da sua libertação. Procurarei defender, assumindo todos os riscos que isso significa uma dimensão utópica de uma Educação Física escolar fundada no desenvolvimento da liberdade, da comunicação, expressividade, igualdade e apoio mútuo.

\section{A EDUCAÇÃo FÍSICA E O PROCESSO dE CONHECIMENTO}

A Educação Física na escola, historicamente, tem se caracterizado por uma prática autoritária onde há predominância de conteúdos de ensino como um ato de "transmissão-assimilação" de conhecimentos estático e fragmentado. Esta questão é bastante evidente nas aulas quando o professor exige do aluno não a compreensão do esporte e dos seus códigos disciplinares, mas a memorização de várias sequiências técnicas, conforme o padrão demostrado a priori. Este modelo de Educação Física considera o aluno tanto melhor quanto mais informações ele conseguir armazenar, independente do interesse que as mesmas possam despertar.

O autoritarismo está presente, principalmente, nas decisð̃es que são sempre tomadas e controladas pelo professor. Ele é a autoridade máxima e na "sua" aula ninguém pode questionar, discutir ou divergir de sua decisão, pois quando isto ocorre utiliza-se de meios coercitivos para que os alunos tenham o comportamento que deseja.

Esta forma de relação perpetua a "adaptação" e o "ajustamento" do aluno ao mundo, anulando qualquer iniciativa de criatividade. A utilização de formas padronizadas e repetitivas dá origem a práticas pedagógicas que raramente põem o aluno na condição de autor do conhecimento. Desta maneira os mesmos

\footnotetext{
* Núcleo de Estudos Pedagógicos de Educação Física/NEPES/CDS/UFSC.
} 
são conquistados por ações paternalistas, percebendo o mundo de forma ingênua e descontextualizada ao qual devem se ajustar.

Penso que só se concretizará uma educação para a libertação quando o discurso/ação dos educadores deixar de ser autoritário, mas, para isso, é preciso que ocorram também transformações radicais nos modos de ser, pensar e agir dos mesmos.

A dimensão fundamental, do processo educativo consiste no ato de conhecer. Conhecer é estar em relação ativa com o mundo dos objetos que se conhece, aí incluídos os sujeitos que se comunicam.

Creio que para se chegar a este conhecimento, é preciso abandonar os discursos vazios, desvinculados da prática e viver o espaço privilegiado do diálogo, da descoberta do novo, da superação dos desafios. Acredito, assim como Freire (1977), que todo o conhecimento começa pela curiosidade, por uma pergunta. Sabemos também, porque muitos professores preferem dar respostas a perguntas não feitas. A forma mais fácil de trabalhar é com a pedagogia da resposta, porque na mesma o professor não corre o risco de equivocar-se. No entanto, entendo que é o equivocar-se que justamente faz com que ele refaça o seu pensar, avançando no conhecimento. Ao mesmo tempo podemos questionar: como avançar no conhecimento da Educação Física se é permitido aos alunos apenas "reproduzir" movimentos padronizados?

Neste contexto é preciso levar em conta, também, que os professores de Educação Física são formados por uma escola que não aceita idéias divergentes e continuam a ser educados por uma sociedade baseada na produtividade e no consumo. Isto significa dizer que estamos a exigir destes professores comportamentos contrários ao que lhe é cobrado e no qual foi e está sendo formado. Como podem ousar se lhes foi ensinado apenas a obedecer?

Acredito que o aluno só conhecerá se o professor lhe provocar a curiosidade. Se houver busca constante no sentido de entender melhor aquilo que faz. Kunz (1991) entende que as aulas de Educação Física devem utilizar-se da tematização do esporte no sentido dos alunos compreenderem melhor este fenômeno sócio-cultural, o que não pode acontecer somente por sua ação prática, mas, principalmente, pela ação-reflexiva.

Para isto é fundamental que se exclua a idéia de conhecimento como dominação e como depósito de conteúdos. As aulas de Educação Física demonstrativas e os métodos de controle vão dar lugar à problematização conjunta que professor e alunos fazem das relações entre os homens e destes com o mundo.

A proposta que trago, é de denunciar a morte da curiosidade na Educação Física, resgatando a paixão de conhecer mais e melhor o movimento humano vivido num espaço significativo de liberdade, catalizando as diferentes maneiras de aprender a experiência.

Aparece então o desafio: como encaminhar um conteúdo na Educação Física que satisfaça a sede de movimento dos alunos e ao mesmo tempo contribua para a melhoria do processo criativo-reflexivo? Desafio este tanto mais sério, quanto mais se reconhece a ambiguidade do processo educativo.

Tenho claro, no entanto, que o processo criativo-reflexivo só é possivel ocorrer num ambiente onde e quando há liberdade. A liberdade a que me refiro não é não ter compromisso, mas sim aquela que compromete o aluno exclusivamente consigo mesmo, exigindo dele disciplina interior, e ao mesmo tempo desobediência contra os autoritarismos que podem colocar em perigo este compromisso.

Creio que a rebeldia é pressuposto da criatividade. Por isso penso que a educação não pode fundamentar-se em valores que contribuam para a domesticação do aluno e sim para a resistência da disciplina que é imposta. A disciplina não se impõe, se busca na relação entre autoridade e liberdade. Não é possível que se deseje criar disciplina intelectual castrando a imaginação, a expressividade do aluno e do mundo que o cerca.

Percebo enquanto professor em final de carreira, que a limitação da margem de liberdade constante, produz antes de tudo no aluno uma atuação passiva e receptiva, desembocando em apatia e frustração.

Para Morais (1986) a autoridade do professor nada tem a ver com policiamento, tem a ver sim com a conquista de uma disciplina de vida que não se aprende através de padrões, mas na própria experiência pedagógica.

Por outro lado Freire \& Schur (1986) argumentam que a natureza do processo educativo é sempre "diretiva", não importando se a educação é feita pela burguesia ou pela classe trabalhadora. No entanto, é preciso saber que diretividade é essa, de que modo ela é e em nome de que ou de quem ela é exercida. Diz o autor que o papel diretivo do educador deve ser no sentido de que os alunos assumam com 
lucidez o seu tempo, entendendo a história como possibilidade, enquanto o futuro é algo que vai se dando. Isto significa que o futuro existe na medida em que se vai modificando o presente.

Nada mais coerente, portanto, do que lançar os alunos à experiência do debate e da análise dos seus verdadeiros problemas, criando condiçðes para que possam optar e decidir sobre os mesmos. E, para que isto aconteça, creio que a exigência básica deva ser a comunicação.

\section{A EDUCAÇÃO FÍSICA E O PROCESSO dE UNIFORMIZAÇÃO}

A Educação Física ao longo do tempo tem servido para controlar a manifestação expressiva do ser humano, utilizando-se para isto de modelos hierárquico, disciplinar e de organização - tais como o modelo biomédico, militarista e esportivo - que é justificado pela chamada, uniforme, submissão a ordens estabelecidas e, principalmente, pela aceitação de processos avaliativos incoerentes.

A uniformização homogeniza comportamentos para que as diferenças se destaquem do padrão instituído e possibilite desta forma o controle dos desvios, detectando os alunos que contestam. $\mathrm{O}$ aluno que não cumpre com o instituído é tomado pelo professor de Educação Física como parâmetro de comportamento desviante/indesejável, criando no mesmo o sentimento de culpa. É através deste controle que a Educação Física classifica e pune, utilizando-se para isto, o processo competitivo. Desta maneira a aceitação das normas por parte dos alunos passa a se constituir numa peça básica para o controle disciplinar. Por isso existe por parte dos profissionais desta área a utilização de mecanismos de defesa, recusando a novidade e a crítica, porque isto põe em perigo o seu próprio conhecimento e da instituição que ele defende como se fosse sua.

Creio, no entanto, ser ingênuo de nossa parte enquanto educadores, solicitar à classe que está no poder colocar em prática uma proposta que desenvolva a autonomia nos alunos, quando esta classe tem claro que a mesma poderá atuar contra ela.

Freire (1979) escreveu que o educador revolucionário precisa utilizar-se de meios para "romper com as amarras impostas pelas normas burocráticas" da escola, desvelando assim a realidade ocultada.

A escola deveria ser um espaço de pensamento e ação divergente, dedicada ao cultivo do saber de forma livre, visando a circulação e difusão das idéias, mas isto não ocorre. Há sim uma preocupação excessiva com a hegemonia das idéias.

É preciso pensarmos com maior clareza a escola e sua burocracia, não em função de modelos, mas em vista de pressupostos que a desafiem.

Lapassade (1989) reconhece que na consciência das burocracias a fidelidade à organização das suas estruturas termina por tornar-se um dever absoluto, uma fonte de valores e de satisfações. São desenvolvidos no interior da burocracia um conjunto de modelos, comportamentos, todo um saber que resiste à mudança. Este autor diz ainda que as decisões das instituições escolares são tomadas sempre pela cúpula do sistema hierárquico através do quadro de sistema de normas e desta forma, a burocracia delega poderes, produz regras, estatutos, papéis, obrigações, e sanções, retirando dos seres humanos o poder de decisão, de iniciativa, de responsabilidade de seus atos. E, em nome da dita "competência burocrática" esquece-se do desejo, assumindo o mundo que não é seu e sim do outro.

\section{O GESTO E A PALAVRA COMO MEDIADORES DO UNIVERSO SIGNIFICATIVO}

A interlocução só ocorrerá se acreditarmos que os alunos têm algo a dizer e que, por isto mesmo, podem construir para a construção da aula. É na interlocução que o professor e alunos aprendem, pois, precisam a cada momento "re-fazerem" a sua forma de dizer de outra maneira o que haviam dito anteriormente. No entanto, penso que os alunos só se sentirão com coragem de se expressar quando o professor não se utilizar de métodos coercitivos/autoritários, valorizando-os como interlocutores legítimos e derrubando o sentimento de ignorância e incapacidade interiorizado pelos mesmos.

Ao estabelecermos como necessidade fundamental a participação do aluno de forma autônoma no processo educativo, creio que a primeira medida é identificar as "situações opressoras" que se tornam 
"habituais", descobrindo aquilo que reprime ou distorce o diálogo, problematizando-as e, a partir destas, chegar a novas formas de agir.

A proposta de Educação Física que defendo a partir de minha vivência prática deve contraporse às padronizações estabelecidas do movimento humano, problematizando-as, no sentido de repensá-las como capacidade que o homem tem de viver a sua corporeidade.

Santin (1987) explica que a comunicação intersubjetiva pelo qual o homem se torna visivel aos outros acontece pelo gesto e pela palavra que são fenômenos corporais e que possuem significado. Neste sentido, o gesto e a palavra são mediadores do universo significativo do homem, implicando em comunicação expressiva. Desta forma a expressividade do gesto humano com sentido/significado adquire dimensões valorativas.

O movimento humano na Educação Física tem sido interpretado quase que exclusivamente como movimento preocupado com a capacidade de rendimento físico, no sentido biomecânico, estático, alienado, quantificável e reprodutivo. Sabemos que esta é a grande estratégia da sociedade capitalista, reduzir o sentir do homem a formas controláveis de manifestação. No entanto, creio que isto é impossível, porque as formas de sensibilidade escapam aos controles e se manifestam em liberdade.

Penso que a Educação Física deve preocupar-se com o que está "faltando", isto é, deve reconhecer e fazer ver que existem outros sentidos além daqueles que se manifestam na estrutura existente.

A proposta que defendo não tem um modelo, caracteriza-se pela colocação de desafios, tematizando as práticas educativas e seus conteúdos, constituindo-se num lugar por excelência da preocupação dos "limites e das possibilidades" dos alunos frente ao mundo. Sendo assim, deve permitir em relação aos seus conteúdos um pluralismo de opçðes onde haja o desafio de experiências de movimento e jogos, percebidos enquanto memória coletiva. Desta forma os conteúdos não são colocados/dados a priori pelo professor, mas sim investigados junto aos alunos, percebendo as suas situações limites no sentido de superá-las.

Especificamente, no ensino dos esportes, penso que o aluno deveria ter condições de aprender tanto a realidade esportiva como social, entendendo-as como uma invenção social do homem e que, por isso mesmo, pode ser modificável. Entendo, portanto, que é preciso questionar todas as instâncias burocrátivas e suas relações de poder tais como: a Escola, o Esporte, o Estado, a Família, a Igreja, os Partidos. É através do questionamento que os alunos começam a perceber que isto tudo não é "natural", vendo os fatos como algo que pode ou não existir, distinguindo entre as normas em vigor na sociedade e a validade das mesmas.

Creio que para que isto ocorra, precisamos negar a pedagogia autoritária ainda presente na Educação Física que leva o aluno à adaptação através do esporte de rendimento; à rivalidade no sentido de sobrepujar o adversário; à nudez quando o esporte adquire o caráter de inquestionabilidade; à reprodução quando só se repete aquilo que é demonstrado como correto; à dominação quando só é permitido fazer o que os códigos esportivos determinam (Siebert, 1992).

Em oposição ao modelo do esporte de rendimento temos experimentado em aulas de Educação Física a utilização do esporte enquanto campo de socialização, onde cada elemento do grupo executa formas múltiplas de interação comunicativa, cooperativa e criativa. O que pretendemos não é negar o esporte, mas fazer com que os profissionais desta área e os alunos compreendam o que está por trás do mesmo, apontando sua estrutura autoritária, possibilitando desta forma a sua modificação no espaço escolar e de lazer.

Entendo que não podemos pensar a Educação simplesmente como obra da escola, pois o que educa é a sociedade como um todo. Na verdade, a escola pouco oferece de possibilidades diversificadas para 0 aluno, ao contrário, ela intervém quase sempre dando o modelo que deve ser repetido.

Acredito que o profissional de Educação Física deve utilizar-se de conteúdos culturais relativos a arte que permitam a expressividade, a comunicação, a criatividade, a cooperação. Isto tudo trabalhado de maneira aventurosa, na mudança, na novidade e em situação não coercitiva, fornecendo oportunidade para 0 desenvolvimento das necessidades fundamentais dos alunos.

Neste sentido podemos trabalhar com a pesquisa (por exemplo: memória dos jogos/dança/esportes/ginástica), mobilizando os alunos a compreender o mundo, colocando obstáculos que eles possam superar um a um, fazendo apelo a tudo o que eles dispð̃em. Isto geralmente não ocorre em aulas de Educação Física porque não se entende experimentação como aprendizagem, como inovação cultural para saber mais, para modificar, para diferenciar o que é válido daquilo que não é. 


\section{CONSIDERAÇÕES FINAIS}

A Educação Física precisa, desta forma, assumir os vínculos do que é possível realizar no momento, alongando os espaços condicionais de liberdade, resgatando o passado (memória) e agindo no presente, porque é ele que vai garantir o futuro. O possivel deve ser portanto conquistado, inventado e construido de forma diversificada. Isto constitui-se num desafio que precisa reconstruir/reinventar formas e conteúdos da atividade educadora que enfrentamos e ao mesmo tempo reinventar a nós mesmos, constantemente. Precisamos, desta forma, amar os riscos, experimentar novas possibilidades de aventurarmos por caminhos perigosos, pioneiros, sem nos preocuparmos com a hegemonia de pensamentos.

Sendo assim, penso que, por um lado, temos o que ensinar sim, mas não acredito que apenas modificando o conteúdo iremos transformar a Educação Física escolar. Por que digo isto? Porque é comum vermos na Universidade e nas escolas, professores ditos "progressistas" que utilizam-se de discursos/conteúdos críticos, politizados e agem de forma bastante autoritária com os alunos, fazendo com que os mesmos apenas repitam "slogans" de esquerda sem, no entanto, modificarem a sua ação perante todas as formas de dominação, desigualdade e autoritarismo vivenciados nestas instituiçðes.

Entretanto, poderia ser questionado: por onde começar? Do meu ponto de vista, por uma concepção de educação não autoritária. Por um outro tipo de escola que funcione como um projeto coletivo e como centro de cultura onde cada um possa ensinar ao outro aquilo que sabe. Creio que o mais importante para um educador enquanto não se consegue criar este tipo de escola é que ele se pergunte constantemente. .

- que tipo de homem/sociedade objetiva formar;

- que objeto de conhecimento pode colaborar para se chegar a este objetivo;

- que metodologia utilizar para que o aluno tenha curiosidade de conhecer;

- como conseguir a interlocução com os alunos;

- qual a forma de avaliação que vai possibilitar chegar a esse objetivo?

$\mathrm{E}$, por fím, deixo uma pergunta-desafio: será que essa instituição escolar que aí está vai permitir a formação deste indivíduo que pretendemos formar enquanto educadores?

\section{REFERÊNCIAS BIBLIOGRÁFICAS}

FREIRE, P. Educação e mudança. 14.ed. Rio de Janeiro, Paz e Terra, 1979.

Extensão e comunicação. 10.ed. Rio de Janeiro, Paz e Terra, 1977.

FREIRE, P.; SCHOR, I. Medo e ousadia: o cotidiano do professor. Rio de Janeiro, Paz e Terra, 1986.

JOYEUX, M. Reflexão sobre a Anarquia. São Paulo, Terra Livre, 1992.

KUNZ, E. Educação Fisica: ensino \& mudanças. Ijuí, UNIJU!, 1991.

LAPASSADE, G. Grupos, organizaçōes e instituiçōes. Rio de Janeiro, Francisco Alves, 1989.

MORAIS, R. Sala de aula - que espaço é este? 2.ed. Campinas, Papirus, 1986.

SANTIN, S. Educação Física: uma abordagem filosófica da corporeidade. Ijui, UNIJUi, 1987.

SIEBERT, R.S.S. Dominação e autoritarismo na prática pedagógica de Educação física e as possibilidades de sua superação. Florianópolis, 1992. Dissertação (Mestrado) - Universidade Federal de Santa Catarina. 